\title{
Pyoderma gangrenosum in a newborn - Case report
}

\author{
Pioderma gangrenoso em recém - nascido - Relato de caso
}

\author{
Francisca Regina Oliveira Carneiro ${ }^{1}$ \\ Brena Andrade de Sousa ${ }^{3}$ \\ Gabriela Athayde Amin ${ }^{3}$
}

\author{
Maria Amélia Lopes dos Santos² \\ Carla do Socorro Silva do Nascimento ${ }^{3}$ \\ Ana Thais Machado Moutinho ${ }^{3}$
}

DOI: http://dx.doi.org/10.1590/abd1806-4841.20132601

\begin{abstract}
Pyoderma gangrenosum is a rare, inflammatory, chronic and recurrent disease of unknown etiology, characterized by noninfectious, necrotizing and painful cutaneous ulcers. Usually it affects adults aged between 25 and 54 years old and rarely children (less than $4 \%$ ), in which it mainly affects the head, face, buttocks, genital and perianal region. The disease presents a quick response to systemic corticosteroids. We report a case of a newborn with hemorrhagic and necrotic ulcers, distributed in the abdomen, buttocks and genital region with rapid and effective response to oral prednisone.
\end{abstract}

Keywords: Adrenal cortex hormones; Pyoderma gangrenosum; Infant, newborn

Resumo: O Pioderma gangrenoso é uma doença inflamatória rara, crônica e recorrente, de etiopatogenia desconhecida, caracterizada por uma ulceração não-infecciosa, necrotizante e dolorosa da pele. Geralmente, afeta adultos na faixa de 25 a 54 anos e raramente crianças (menos de $4 \%$ ), nestes acomete preferencialmente cabeça e face, nádegas, região perianal e genital. Apresenta rápida resposta à corticoterapia sistêmica. Relata-se um caso de recém-nascida com lesões ulceradas de pioderma gangrenoso de fundo hemorrágico e necrótico distribuídas em abdômen, região genital e glútea com resposta rápida e efetiva à prednisona oral.

Palavras-chave: Corticosteróides; Pioderma gangrenoso; Recém-nascido

\section{INTRODUCTION}

Pyoderma gangrenosum (PG) is a rare, chronic and recurring condition, characterized by necrotizing, painful non-infectious skin ulcerations. ${ }^{1,2,3}$

PG was first described in the XX century by Brocq. Later, in 1930, it was name by Brunsting et al.,who believed that streptococcal infection was a significant component of the disease, causing secondary cutaneous gangrene and therefore they named it pyoderma gangrenosum, a name nowadays recognized as erroneous. ${ }^{1,4,5}$

It is a neutrophilic dermatosis, with an unknown pathogenesis, that may however, in over $50 \%$ of the cases, be associated to systemic illnesses, such as Crohn's disease, ulcerative colitis, polyarthritis, diabetes mellitus, myelodysplastic syndromes or myeloid leukemia, monoclonal gammopathy and systemic lupus erythematosus..$^{2,6,7}$
This disease may occur at any age, without a gender preference, but usually it affects adults from 25 to 54 years old and very rarely, children (less the $4 \%$ of the cases). $)^{1,2,7,8}$

From the clinical standpoint it is characterized by an erythematous nodule or hemorrhagic pustule that evolves progressively with necrosis and formation of a painful ulcer, with irregular, violet and undermined edges, involved in an erythematous halo. Lesions might be unique or in multiples and typically, they exhibit a cribriform cicatrization pattern. ${ }^{5}$ There are 4 clinical variants described for PG: ulcerative, pustular, bullous and vegetative type, of which ulcerative is the most common form..$^{4,6}$

The most commonly affected areas are the extremities, especially the lower limbs, but it can also affect head, face, arms, hands, torso, and periorbital and periorificial regions, including mucocutaneous

\footnotetext{
Received on 08.03.2013.

Approved by the Advisory Board and accepted for publication on 20.03.2013.

* Work performed at the dermatology service at Pará State University (UEPA) - Belém (PA), Brazil.

Conflict of interest: None

Financial Support: None

MD, PhD in dermatology at the São Paulo Federal University (UNIFESP) - Adjunct Professor at Pará State University (UEPA) - Belém (PA), Brazil.

MD, specialist in dermatology and hansenology - Professor and Coordinator of the discipline of dermatology on the medical school at Pará State University (UEPA) -Preceptor of the dermatology residency at Pará State University (UEPA) - Belém (PA), Brazil.

MD, resident on the dermatology program at Pará State University (UEPA) - Belém (PA), Brazil. 
zones. ${ }^{8}$ In children, the disease is located on the head and face, buttocks, perianal and perigenital regions, with a prevalence of pustular lesions. ${ }^{2,9}$

Differential diagnoses include ecthyma gangrenosum, infection by atypical mycobacteria, deep mycosis, nodular vasculitis and Sweet syndrome. ${ }^{1,6}$

The most prescribed treatment for children is systemic corticoid therapy, which is generally effective. Alternative therapies include dapsone, sulphapyridine, cyclosporine, methotrexate, clofazimine, minocycline and colchicine. ${ }^{1,2}$

\section{CASE REPORT}

A twenty-three days old, female patient, born and living in Primavera (Pará State), was admitted to the neonatal intensive care unit (NICU) presenting with "wounds" on the abdomen, genital area and buttocks for the last 10 days. The mother informed that the problem started with a "swelling" and blisters that ruptured, originating the "wounds" on the aforementioned areas. Dermatological examination showed ulcerated lesions, some with a granular hemorrhagic base others with purulent and necrotic ones; with irregular and excavated borders, located on the torso and genital-inguinal-crural areas, extending to the buttocks (Figures 1 and 2). The anatomopathological examination of the biopsy specimen showed an epidermis with parakeratosis, without other significant associated alterations. The dermis presented with a vascular ectasia and a perivascular, interstitial inflammatory infiltrate of a lymphohistiocytic nature, scattered with eosinophils and rare neutrophils. No histological marker of vasculitis was observed. The infiltrate extended to the subcutaneous interstice, both in

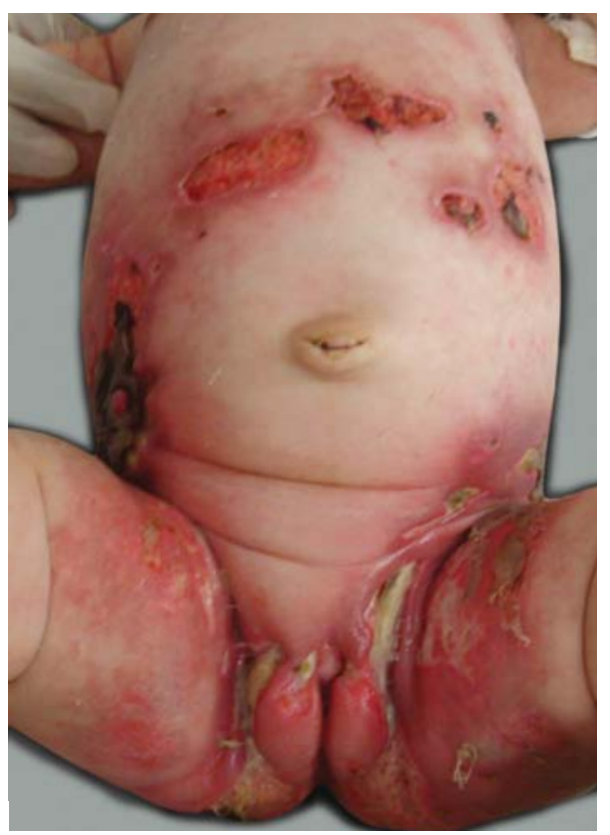

Figure 1 U 1 c e r a t e d lesions, some with a hemorrhagic granular base, others with a necrotic, purulent base, and excavated irregular borders, scattered on torso, genital-inguinalcrural areas and extending to the buttocks the lobular and septal sectors, giving the diagnoses of sub-acute superficial and deep inflammatory processes. We performed cultures for bacteria on the ulcers' secretion, with a negative result. The patient was treated with wide-spectrum antibiotics, cephalosporin and imipenem, for seven days without response, at which point a dermatologic consultation was solicited, leading to the diagnosis of pyoderma gangrenosum. Systemic corticoid therapy (prednisone 0.5 $\mathrm{mg} / \mathrm{kg} /$ day) was then initiated with marked improvement of the lesions after ten days. The patient was rapidly discharged and sent to the outpatient clinic for corticosteroid weaning. Presently she has only atrophic scars. (Figure 3 )

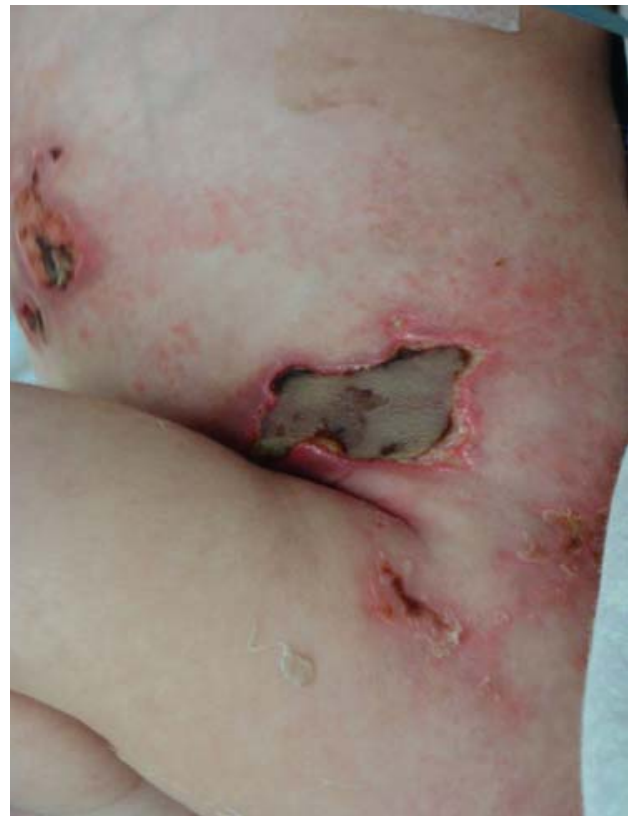

Figure 2:

Details of the abdominal lesions

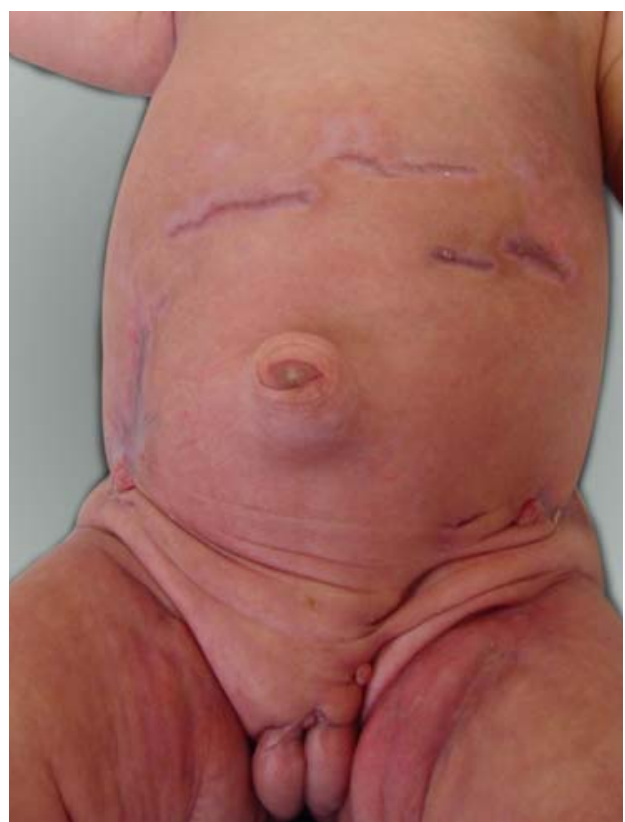

Figure 3:

Atrophic scarring after systemic corticoid therapy 


\section{DISCUSSION}

Pyoderma gangrenosum is a rare inflammatory chronic and destructive disease of unknown etiopathogenesis. It is characterized, initially, by painful nodules and pustules, that increase in a centrifugal and serpiginous pattern until they form purulent-based ulcerations with erythemato-violet, shallow, excavated and irregular borders. ${ }^{1,7}$ The most affected areas are the extremities, buttocks, abdomen and face; however, in children the involvement of head and neck is usual, and in those under one year of age, the genital and perianal areas ${ }^{1}$, as reported in this case. Antecedents of trauma are reported as triggers in many newborns, thus explaining the predominant involvement of diaper-covered areas, similarly to our patient. Likewise, pathergy is another such traumatic event reported as causing PG lesions, same as wound debridement, intradermic injections, vaccinations or surgical scaring. ${ }^{2,5}$

PG is associated to systemic illnesses in about $50 \%$ of the adult cases, however, it is important to highlight that newborns rarely present with systemic diseases, as was the case with our patient, which was healthy. ${ }^{2,7}$

The diagnosis is based on clinical evaluation, after the exclusion of other specific ulcerative processes. ${ }^{7}$ Histopathological exam may be performed, with results ranging from a dense inflammatory infiltrate, predominantly formed by polymorphonuclear leucocytes associated to fibrinoid necrosis of the vascular walls to samples with ulceration and fibrosis, with the addition of a granulation tissue permeated by a mixed inflammatory infiltrate, containing plasma cells and eosinophils. ${ }^{3}$ The histopathological distinction between PG and other ulcerative processes that share dermic neutrophilia is challenging and sometimes

\section{REFERENCES}

1. Sandhu K, Handa S, Kanwar AJ. Idiopathic pyoderma gangrenosum in a child. Pediatr Dermatol. 2004;21:276-7.

2. Torrelo A, Colmenero I, Serrano C, Vilanova A, Naranjo R, Zambrano A. Pyoderma Gangrenosum in an Infant. Pediatr Dermatol. 2006;23:338-41.

3. Wanke NCF, Souza MAA, Régnier GC, Maceira J. Pioderma Gangrenoso: a respeito de dez casos. An Bras Dermatol. 1994;69:175-8.

4. Bhat RM, Nandakishore B, Sequeira FF, Sukumar D, Kamath GH, Martis J, al. Pyoderma gangrenosum: an Indian perspective. Clin Exp Dermatol. 2011;36:242-7.

5. Batista MD, Fernandes RL, Rocha MAD, Ikino JK, Pinheiro RF, Chauffaille MLLF, et al. Bullous pyoderma gangrenosum and myelodysplastic syndrome. An Bras Dermatol. 2006;81:S309-12.

6. Bakhshi S, Sethuraman G, Singh MK, Arya LS. Atypical pyoderma gangrenosum as a manifestation of childhood acute lymphoblastic leukemia. Pediatr Dermatol. 2005;22:543-5.

7. Souza CS, Chiossi MPV, Takada MH, Foss NT, Roselino AMF. Pyoderma gangrenosum: case study and review of clinical, laboratorial and therapeutic aspects. An Bras Dermatol. 1999;74:465-72. unattainable. The massive neutrophilic infiltration on the absence of vasculitis and granulomatous formation speaks in favor of PG. ${ }^{4}$

In 2004, Su et al proposed the diagnostic criteria for PG, listed below:

\section{Major criteria:}

1. Rapid progression of a painful, necrotic cutaneous ulcer with an irregular violaceous and undermined border.

2. Other causes of cutaneous ulceration have been excluded.

\section{Minor criteria:}

1. History suggestive of pathergy or clinical finding of cribriform scarring.

2. Systemic diseases associated with PG.

3. Histopathological findings of sterile dermal neutrophilia and/or mixed inflammatory infiltrate and/or lymphocytic vasculitis.

4. Rapid response to systemic corticosteroid therapy

The presence of one minor and two major criteria would establish the diagnosis of PG; therefore, our patient satisfied the diagnostic principles for this disease. ${ }^{10}$

Systemic corticoid therapy is the treatment of choice, as it is effective in treating the acute, rapid, and progressive forms of the disease; and accordingly, this was the drug administered to our patient, who presented an excellent response. Oral corticoid as well as pulse therapy may equally be used. ${ }^{4}$ This dramatic response to treatment is important, because, together with negative bacterial culture it can help differentiate PG from other causes of perianal abscess in children, like chronic granulomatous diseases. ${ }^{9}$
8. Barbato MT, Bakos L, Masiero NCMS, Bolson P. Clinic and pathological profile of the patients with pyoderma gangrenosum at Hospital de Clínicas de Porto Alegre (RS) Brazil (2000-2006). An Bras Dermatol. 2008;83:431-6.

9. Mehta AJ, Charman CR. Pyoderma gangrenosum in association with autoimmune neutropenia of infancy. Pediatr Dermatol. 2008;25:620-2.

10. Su WP, Davis MD, Weenig RH, Powell FC, Perry HO. Pyoderma gangrenosum: clinicopathologic correlation and proposed diagnostic criteria. Int $\mathrm{J}$ Dermatol. 2004;43:790-800.
MAILING ADDRESS:
Brena Andrade de Sousa
Travessa Perebebuí, 2623 - Marco
66087670 - Belém - PA
Brazil
E-mail: brenasousa@gmail.com

How to cite this article: Carneiro FRO, Santos MAL, Sousa BA, Nascimento CSS, Amin GA, Moutinho ATM. Pyoderma gangrenosum in a newborn - Case report. An Bras Dermatol. 2013;88(6 Suppl 1):S173-5. 